\title{
Drawing texture with the toy piano
}

\author{
Diana Blom
}

Western Sydney University | Australia

\begin{abstract}
This paper discusses the influence of hand drawing techniques in my work for toy piano. It is known that composers often respond expressively to ideas and draw compositional strategies from other domains of life, for example, the mathematical proportions of architecture on some compositions of Guillame DuFay, Peter Maxwell Davies and Eve Duncan. For me, a chance comment from an artist friend, Deanna Petherbridge's book, The Primacy of Drawing: Histories EO Theories of Practice (2010) and Elizabeth Cooper's botanical watercolours of the Australian rainforest tree Stenocarpus sinuatus (Firewheel Tree) offered ideas and techniques for several works for toy piano, and piano and toy piano (one player). While my musical response to hand drawing techniques is largely an expressive response, there is an element of trying to adapt the drawing techniques in a way similar to how artists use them, but in sound.
\end{abstract}

Keywords: drawing techniques, line, pentimenti, toy piano, architecture. 


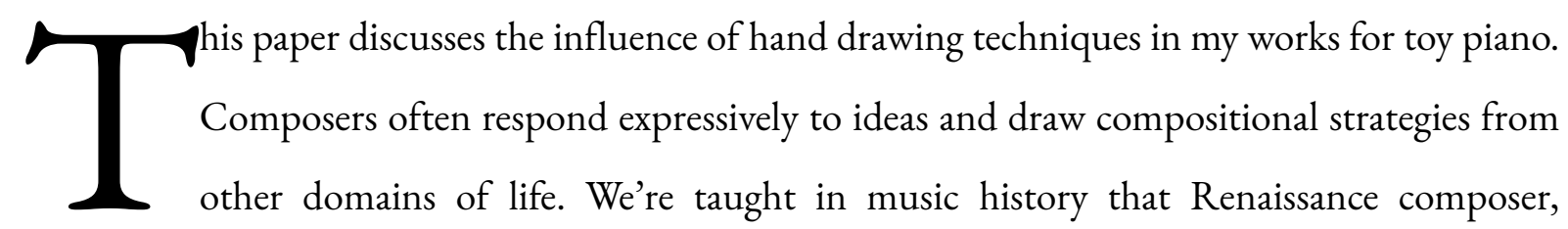
Guillame Dufay's motet, Nuper rosarum florae, incorporated mathematical proportions of Santa Maria del Fiore Cathedral, the dome of which was engineered by Renaissance architect Filippo Brunelleschi. The motet was written for the consecration of the building and Warren (1973) finds that "in its overall dimension ... Nuper rosarum flores has exactly the same proportions as the interior of the cross and dome of Santa Maria del Fiore” (p. 97) - the isometric motet's rhythmic scheme reflects the proportions - 6:4:2:3 - of the cathedral dome. The influence of Renaissance architecture, in particular the churches of Brunelleschi, is also found in Peter Maxwell Davies's Symphony No. 3 with his use of Fibonacci numbers in proportioning the symphony being modelled on these buildings (DAVIES, 1994).

Australian composer, Eve Duncan (2017), refers to two composers who have been inspired by architecture - Liza Lim's Ecstatic Architecture, composed for the 2014 opening of the Walt Disney Concert Hall in Los Angeles and Consecration of the House composed by Ludwig van Beethoven for the opening of the Josephstadt Theater in Vienna in 1822. She calls these "expressive responses to the architecture that do not include incorporating non-musical mathematical architectural parallels in the music” (p. 68). However, in her own work The Butterfly House (2011), for piano quintet, Eve Duncan "uses the architectural plans of the modernist McCraith House, designed by architects Chancellor and Patrick in 1957[,]....the linear and angular proportions of the house ...given a parallel in the musical elements, both mathematically and non-mathematically" (BONSHEK, 2015 - no page number). (Image 1)

IMAGE 1 - McCraith House. Photograph by John Lloyd Fillingham (permission of the photographer)

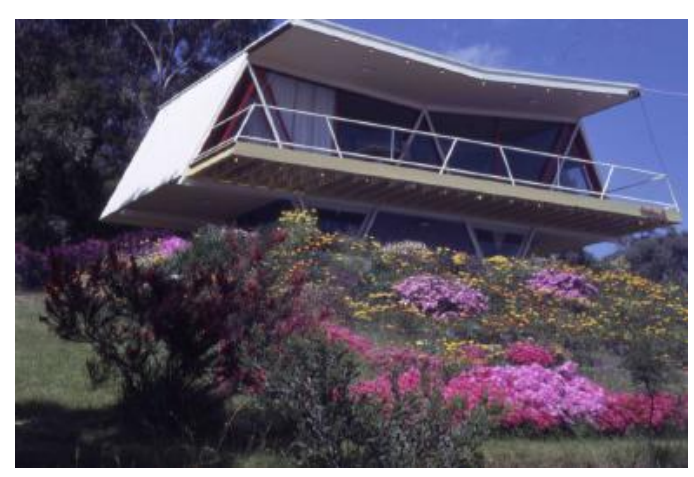


Messiaen links his principle of nonretrogradation (palindrome) to architecture saying “...thus, in ancient art, Gothic and Romanesque cathedrals, and even modern art, the decorative figures are... symmetrically inverse figures...” (p. 12 SAMUEL, 1986, English trans. by E. T. Glasow, 1994). Here, architectural principles and concepts are adopted rather than precise measurements. And composers often draw on the musical strategies of another culture and adapt them to create a rich sound system within which to play and compose - I'm thinking of Olivier Messiaen and Philip Glass's interest in Indian rhythmic patterns. The message is that the systems and principles of other domains and other cultures can be a rich source of compositional ideas and strategies.

For me, it was a passing comment made several years ago by a friend who paints, that reminded me artists have as many processes and techniques as music composers. She saw a painting of people on Sumner Beach, New Zealand, by Derek Margetts, a New Zealand painter, on my wall (see Image 2) and commented on it using an illustrator's style because of a black line around the figures.

IMAGE 2 - Sumner Beach scene, Derek Margetts (1984)

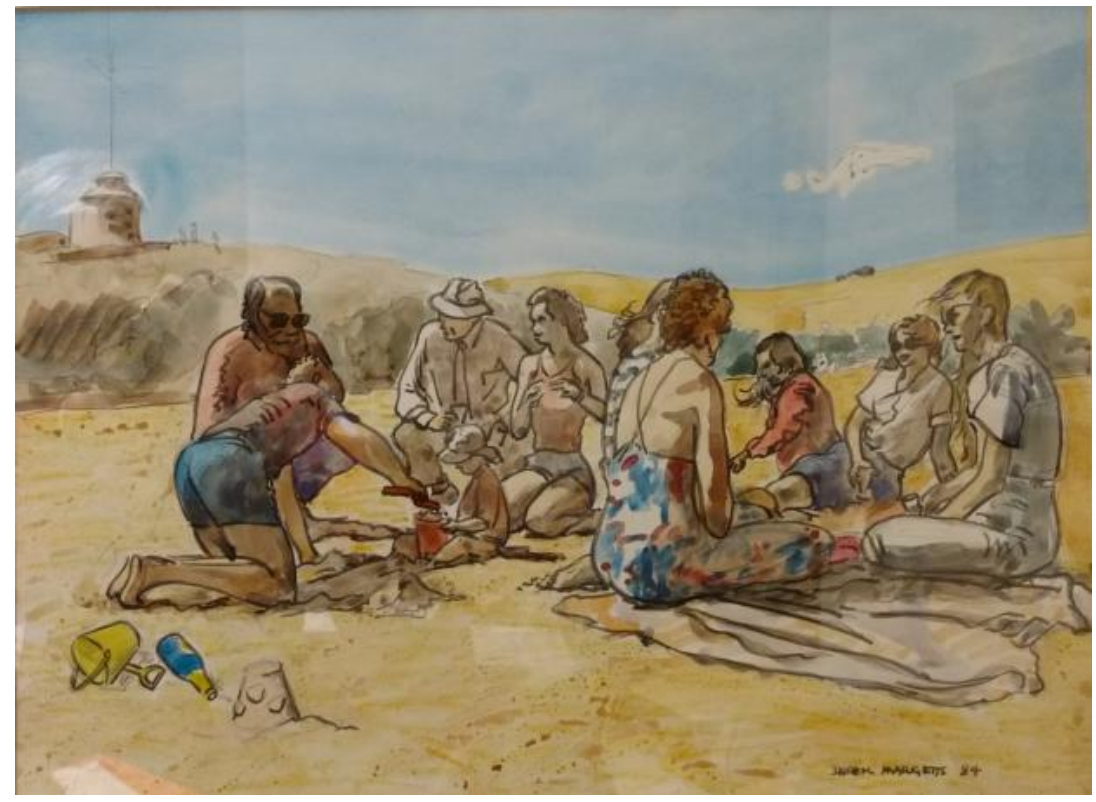

This comment stayed with me and re-emerged when I read Deanna Petherbridge's book, The Primacy of Drawing: Histories $\Xi^{\circ}$ Theories of Practice (2010). Petherbridge explains and illustrates many technical drawing terms - 'Drawing Strategies' (p. 152) she calls them, although sometimes she refers to 'drawing systems' (p.88). In discussing line in drawing, Petherbridge relates to my painter friend's passing comment about an illustrator's style when noting how "the ability of drawing to 
unfold in time at both micro and macro levels means that it readily serves time-based disciplines, from book illustration to comic books, graphic novels or animation” (p. 96). She writes of how 'the basic units of lines, marks and traces and the way that they relate to each other and to the support materials on which they are deployed constitute the primary aspect of the linear economy (p.88)'.

The Blue Ice Cave (2016) for piano and toy piano (one player), composed in 2013, is the first work in which I deliberately drew on the idea of line. It was written for Antonietta Loffredo to play in our collaborative project, Antarctica, new music for piano and/or toy piano by composers from five countries, with the southern continent's landscapes and atmospheres in $\operatorname{mind}^{1}$. The Blue Ice Cave was influenced by a photograph of such a cave taken in Antarctica by Geoff Paul (Image 3), and while the photograph was certainly an influence, the work deliberately explores Petherbridge's idea of line, and in particular the illustrator's line.

IMAGE 3 - The blue ice cave. Photograph by Geoff Paul (permission of the photographer)

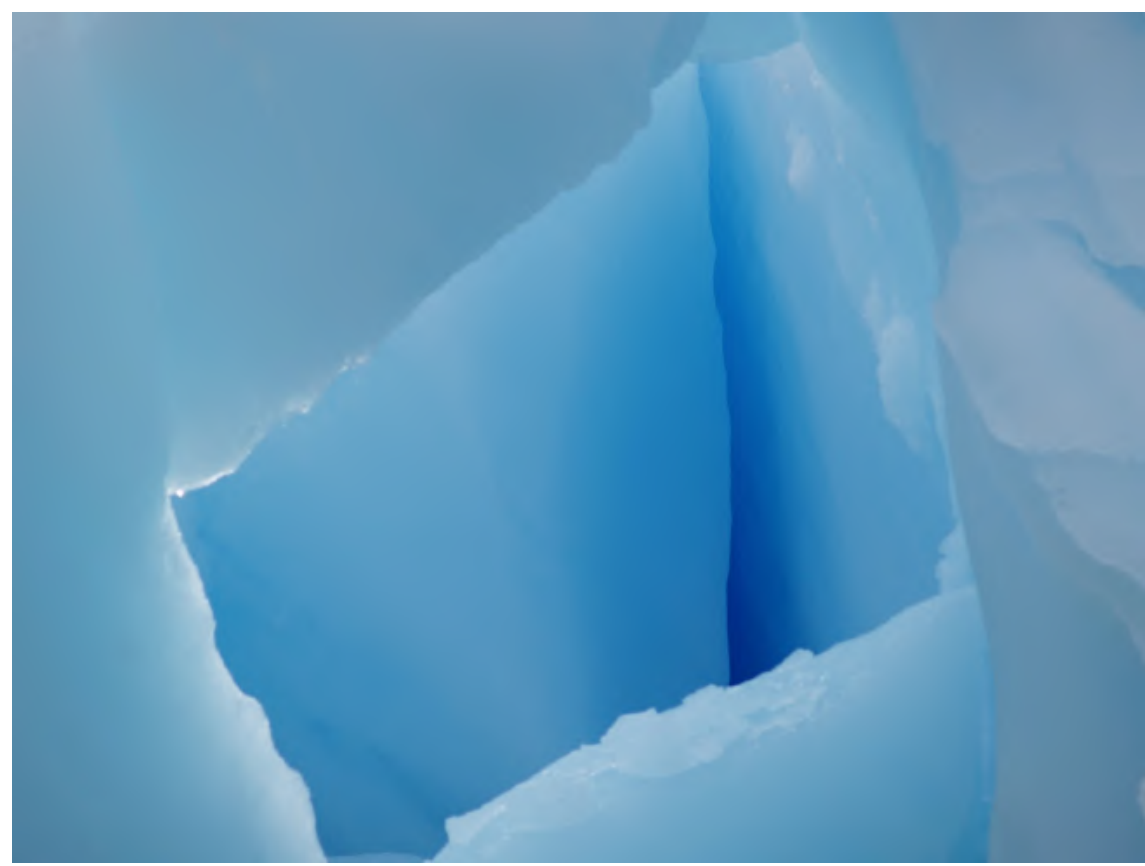

The piano plays the dominant role but the toy piano, when it appears, is, with one exception, always providing a sharp, 'icy' line around the piano's figure - like an illustrator's line sometimes together, measure 32 (Image 4), sometimes in counterpoint, measure 37 (Image 5).

\footnotetext{
${ }^{1} 2014$ Antarctica - new music for toy piano and/or piano - Antonietta Loffredo, piano/toy piano, Wirripang Media Pty. Ltd. CD Wirr 059
} 
IMAGE 4 - The Blue Ice Cave (2016) for piano and toy piano mss 31-33 (permission of Wirripang Pty. Ltd.)

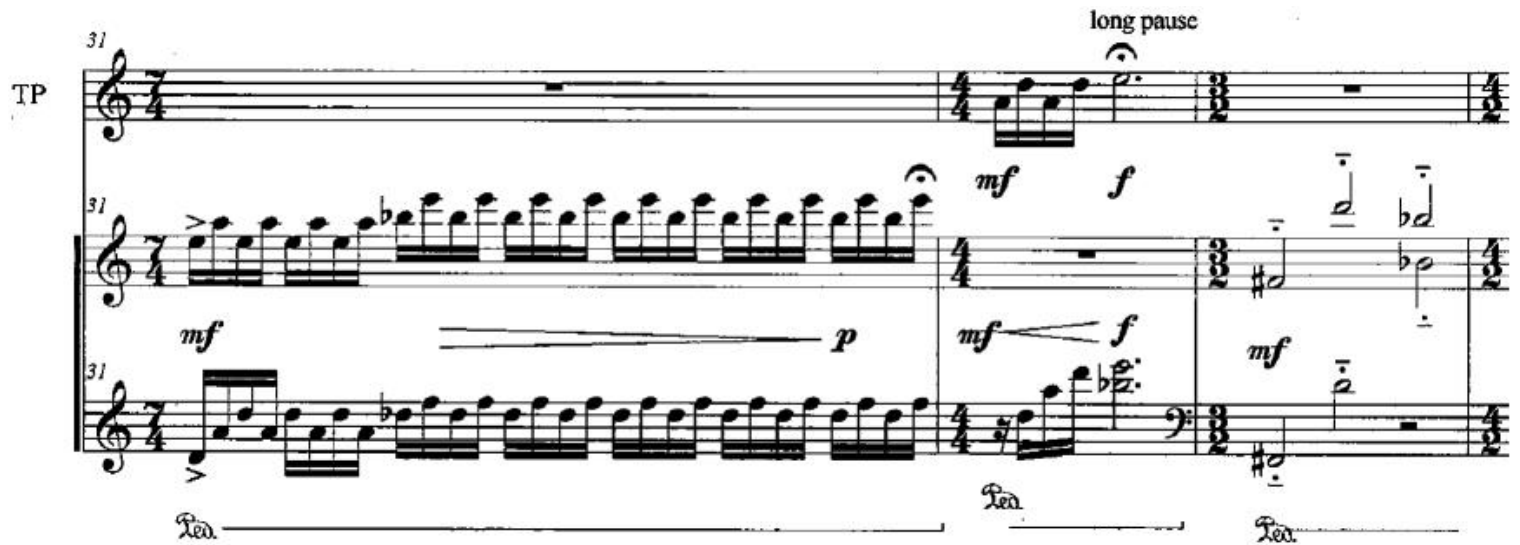

IMAGE 5 - The Blue Ice Cave (2016) for piano and toy piano mss. 34-38 (permission of Wirripang Pty. Ltd.)

TP

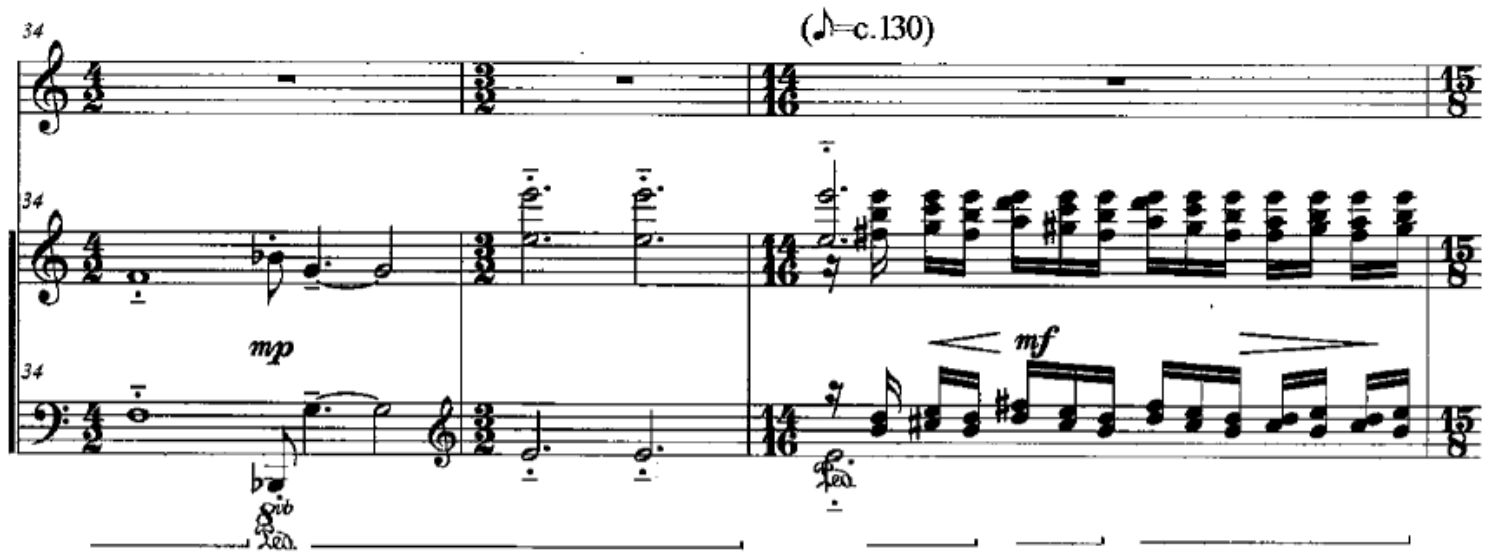

TP

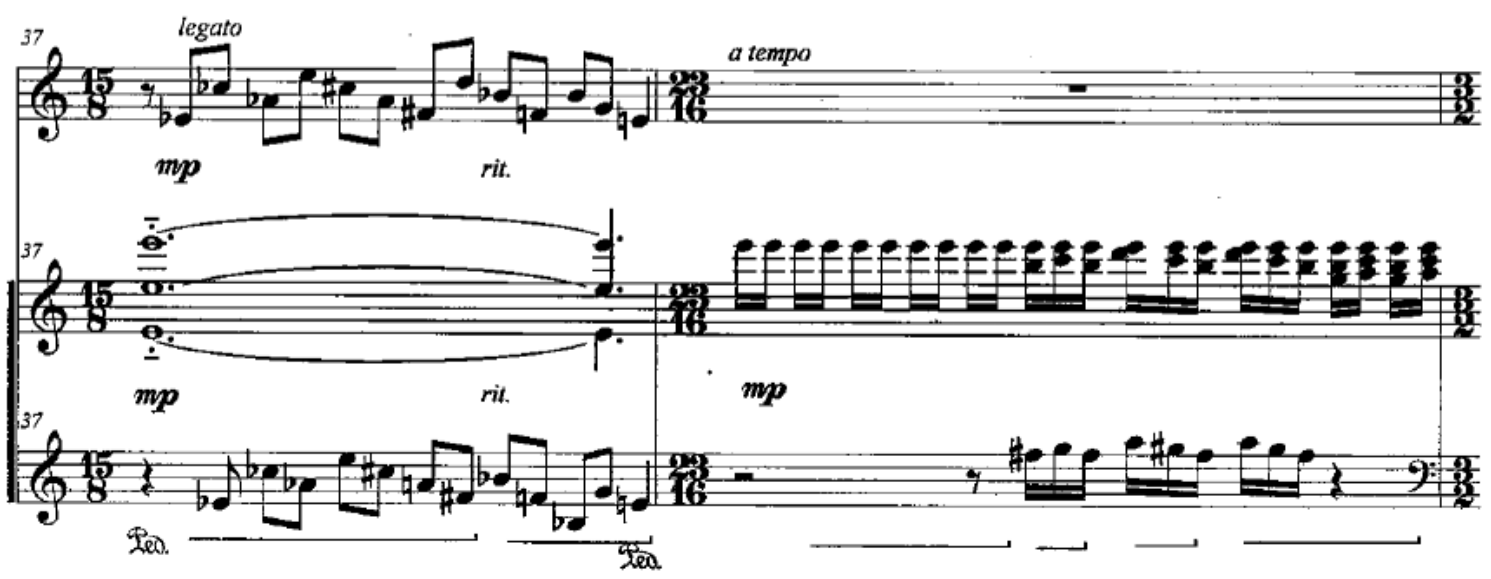

This clear, defining timbral quality of the toy piano complements the softer, more diffuse timbre of the piano and together forms a rich, wider keyboard palette for one player. 
Petherbridge describes how

Lines can be organised into coded systems to approximate the spatial and descriptive aspects of colour or to simulate textures, but unadorned line escapes the inherently sensory/evocative aspects of paint, except in its apparent ability to suggest movement: what the seventeenth-century theorist Franciscus Junuis had referred to as a 'deceitfull similitude of Life and Motion.' (PETHERBRIDGE, 2010, p. 88).

One example of this suggested movement is seen in Henry Moore's (1898-1986) Women Winding Wool (1949)2 which explores "the volume and surface complexities" (Petherbridge, 2010, p. 98) of the figures being drawn. The drawing is described as

\footnotetext{
a modern and expressionist version of this linear code for defining volume and movement... although its potential motion has been knitted into monumental stasis. The curved lines that capture and enmesh the simplified forms of the headless female figures establish a homological relationship with the subject matter of winding' (PETHERBRIDGE, 2010, p. 101).
}

For the viewer, the lines offer an experience of almost being in the wool winding process itself, an immersive experience as a winder and also the conviviality of the paired task. Drawing on this close connection between viewer/listener and the activity, I wrote Through Shadows (2020), a work for toy piano in 2018 for the toy piano festival Music as Play - the toy piano takes the stage $e^{3}$, held in Como, Italy in 2019. The piece was influenced by driving through an avenue of $100+$ year old plane trees in northern Poland, knowing that the Polish government had been told to cut the trees down by the EU as they are considered a hazard to motorists. Leaving politics aside, the moving sensation of the changing volume of shadow, sometimes flickering, sometime very immersive - like Moore's busy wool winders portraying volume and movement - is something the two sections of the work try to capture. Firstly, the flickering (Image 6) where the two hands are in contrary movement interspersed with a lighter figure; and later the immersive quality (Image 7) where the alternating hand blocks seek to capture darker, denser shadow interspersed with light.

\footnotetext{
${ }^{2}$ There are several drawings by Henry Moore titled Women Winding Wool. Petherbridge is referring to the busy 1949 drawing in crayon and watercolour.

${ }^{3}$ https://music-as-play.wixsite.com/toypiano
} 
IMAGE 6 - Through Shadows (2020) for toy piano, mss. 74-80 (permission Wirripang Pty. Ltd.).
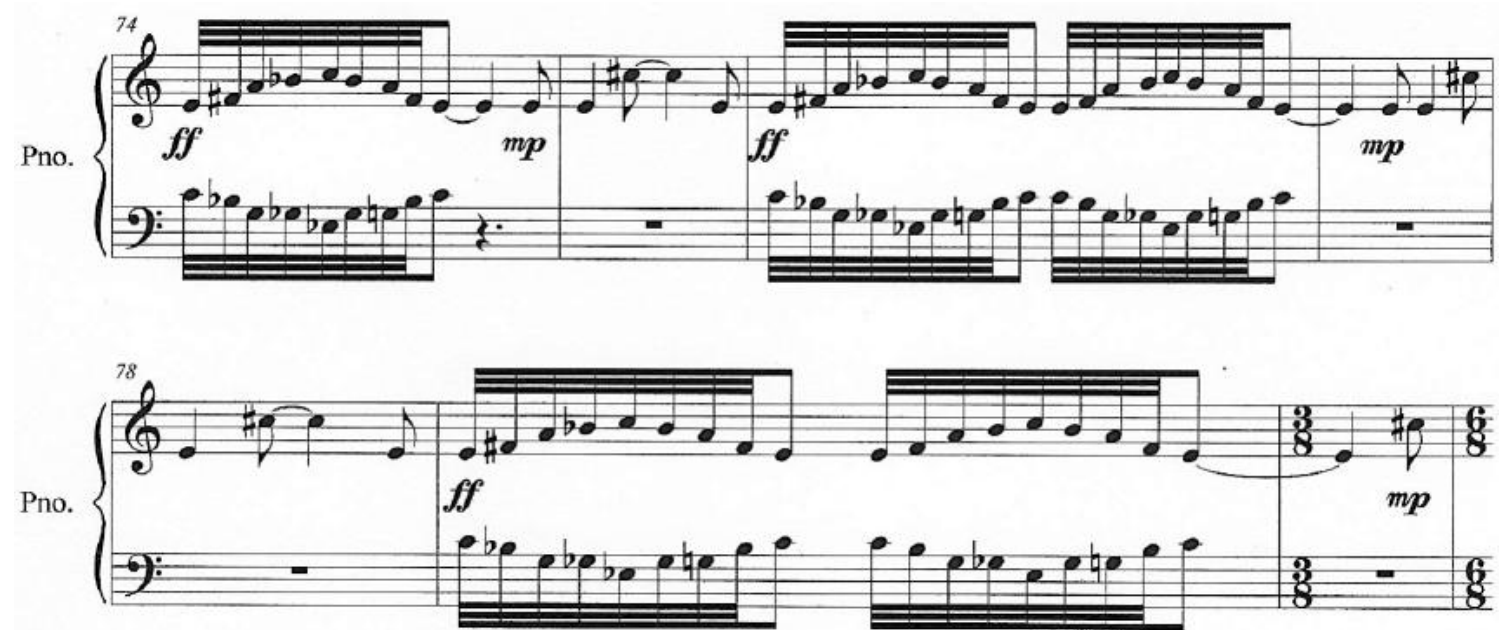

IMAGE 7 - Through Shadows (2020) for toy piano mss 114-119 (permission Wirripang Pty. Ltd.)
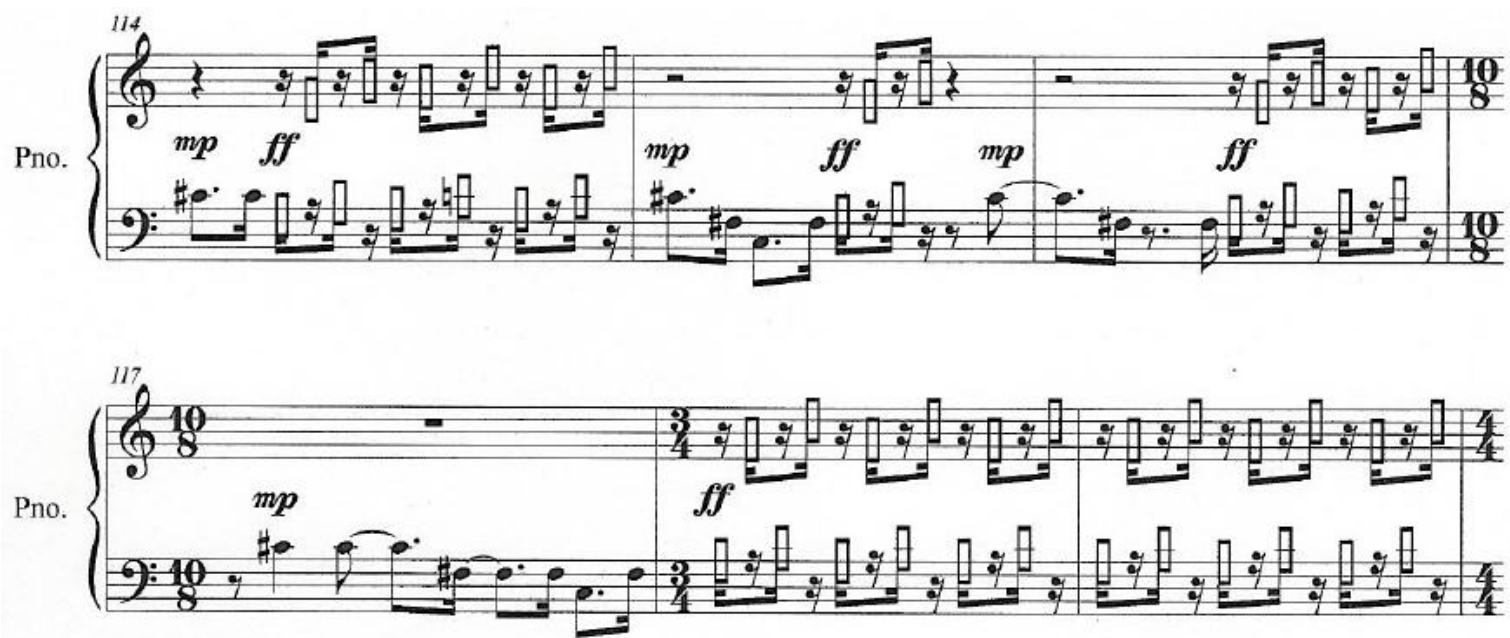

In both these examples, there is a link to Petherbridge's comments on Kandinsky and Klee, both artist/theorists, and their discussions on "lines and shape within a taxonomy of dynamic and passive lines. Line as a dynamic time-trace subsumes a complex layering of signification in the making of drawing and its reception, where it is not easy to unravel actuality and illusion, inherent movement and implied motion and emotion” (p. 90). Driving through shadows experiences this blurring between actuality and illusion, inherent movement and implied motion.

Pentimenti are second thoughts, evidence of traces of previous work where the artist has changed their mind. Petherbridge reminds us that the origin of the word is a 'stroke of repentance [regret]' (p. 31). She writes, 
It is a condition of linearity that unless lines and pentiment $i$ have been deliberately erased, drawing asserts, or has the potential to assert, the fully extended history and processes of its own making.... In this sense, drawing constructs its own narrative of making, distinct but inseparable from its subject matter (PETHERBRIDGE, 2010, p. 92).

In a drawing, pentimenti can be a series of studies on one page but more interestingly, for me, can be the sight of the previous drawing still visible under the second thoughts. In Leonardo da Vinci's The Madonna and Child with a Cat (Image 8) we easily see where the Virgin's head could have been.

IMAGE 8 - Photograph of a Study by Leonardo da Vinci The Madonna and Child with a Cat (c.1480). (@) The Trustees of the British Museum https://www.britishmuseum.org/collection/image/1613428768. Creative Commons Attribution-NonCommercial-ShareAlike 4.0 International (CC BY-NC-SA 4.0))

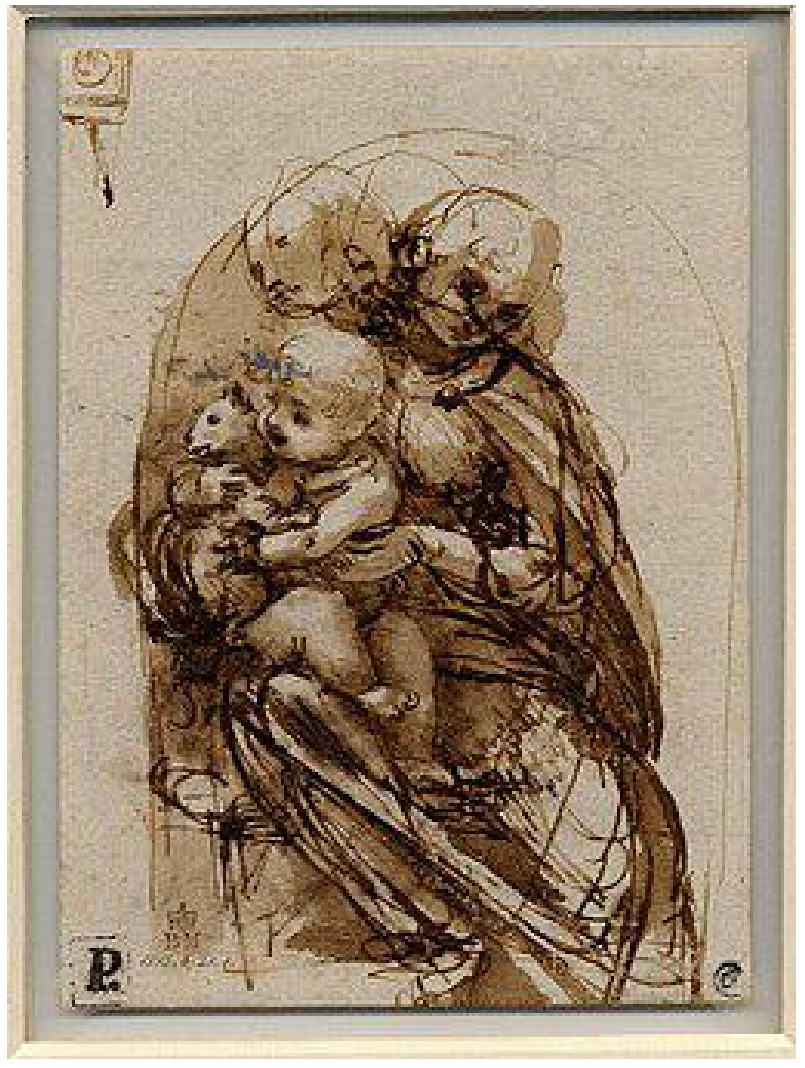

The term 'faux pentimenti' (p. 157) is where artists deliberately show second thoughts and Petherbridge refers to Susan Rothenberg's Untitled, a charcoal drawing of horses, as a work where "the repeated strokes and pentimenti suggest a narrative of primitivism and authenticity" (p. 160). For me, the use of faux pentimenti's many lines in the drawing again indicate movement, not wool winding this time, but movement of unsettled horses, moving to the left of the drawing, for others to the right. 
One of my interpretations of pentimento is the use of pre-existing musical lines from another work or sound world, lines with a previous history. Cat's Play (2018) for toy piano, castanet, horn and bell (Image 9), composed in 2018, outlines Domenico Scarlatti's The Cat's Fugue subject in the lower notes of the toy piano in measures 30-33 at the end of the work - a musician's joke, if you like, and a piece I have learnt and played on the harpsichord. Here, I am placing my history with the Scarlatti work, coupled with memories of a contemporary cat into a recent composition and in doing so seeking, to requote Petherbridge, "to assert, the fully extended history and processes of [a works] own making”.

IMAGE 9: Cat's Play (2019) for toy piano, castanets, horn and bell, mss. 26-34 (permission Wirripang Pty. Ltd.)
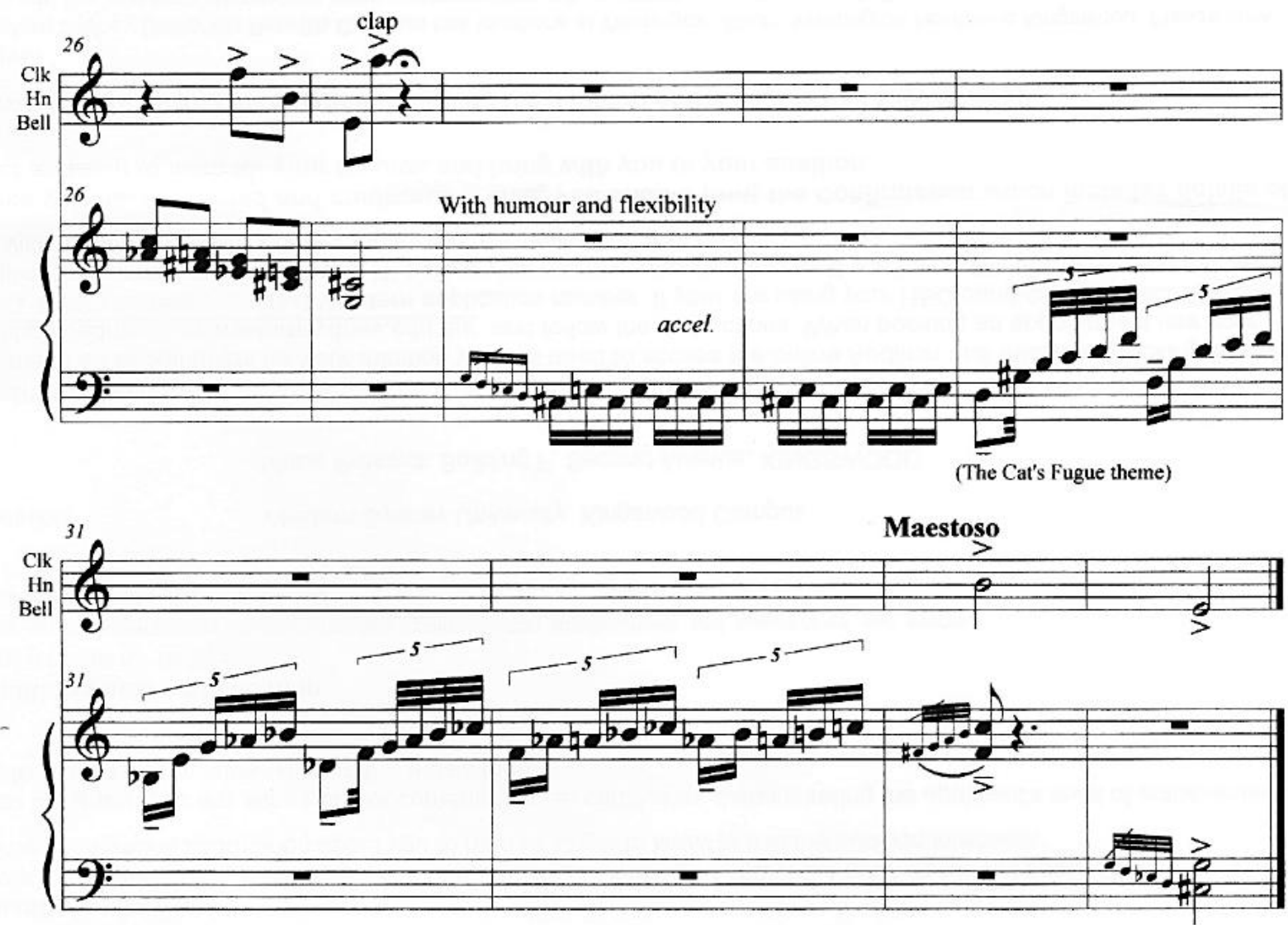

And the work uses hocket, measure 18-25, that is, broken line between the toy piano and the three toy percussion instruments which together sketch a whole shape, a musical device which I argue is a type of faux pentimenti (Image 10). 

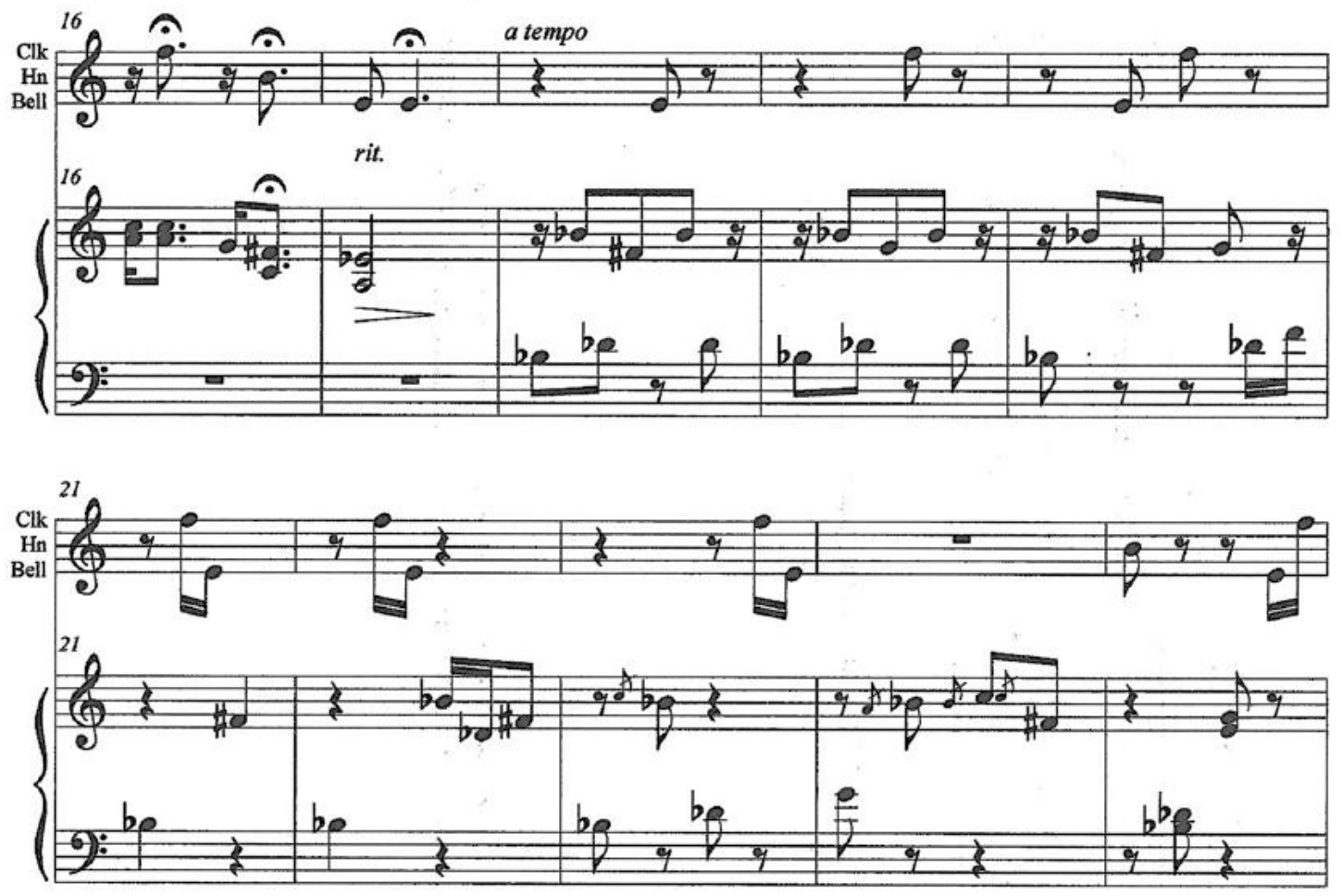

In another work, ...earth tones... for toy piano (2014), composed in 2014, the opening adopts a Bachlike slow movement texture (my own history as a harpsichordist again) and in the final section (Image 11), the sound of three church bell chimes, heard while on holiday in Mostar, Prague and the King's Lynn Minister's 11.30 chime, working with and against each other, end the work. Here musical tourism is a form of history woven through process. 
IMAGE 11 - ...earth tones... for toy piano (2014) mss 58-65 (permission Wirripang Pty. Ltd.)
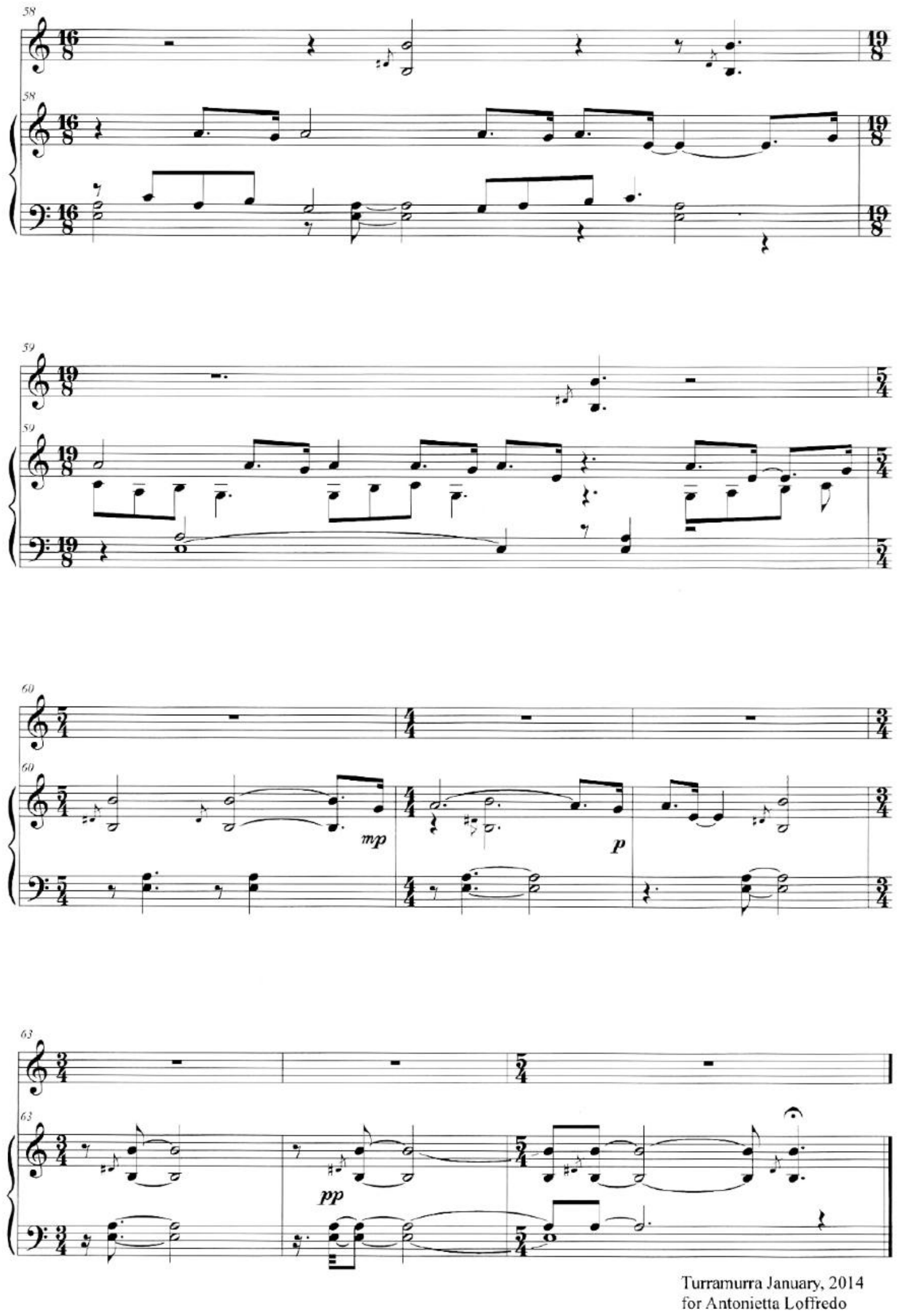
My second interpretation of pentimenti is akin to the compositional process Steve Reich used in his work Drumming (1971). He talks of "the process of gradually substituting beats for rests (or rests for beats) within a constantly repeating rhythmic cycle” (REICH, 1974, p. 58). Kirzinger calls this 'reduction, that is, changing sounded notes to rests; saturation (replacing rests with notes)' (Robert KIRZINGER, 2015). Through Shadows (2020) for toy piano begins with a four-measure pattern in the 'reduction' stage - more rests than notes - adding notes (and gradually repeating each measure of the original four-measure pattern) (Image 12) until the full pattern is revealed then reduced again. This is coupled with repetition of each measure of the four-measure pattern, first twice each, then three times, and so on.

IMAGE 12 - Through Shadows (2020) for toy piano mss 1-10 (permission Wirripang Pty. Ltd.)
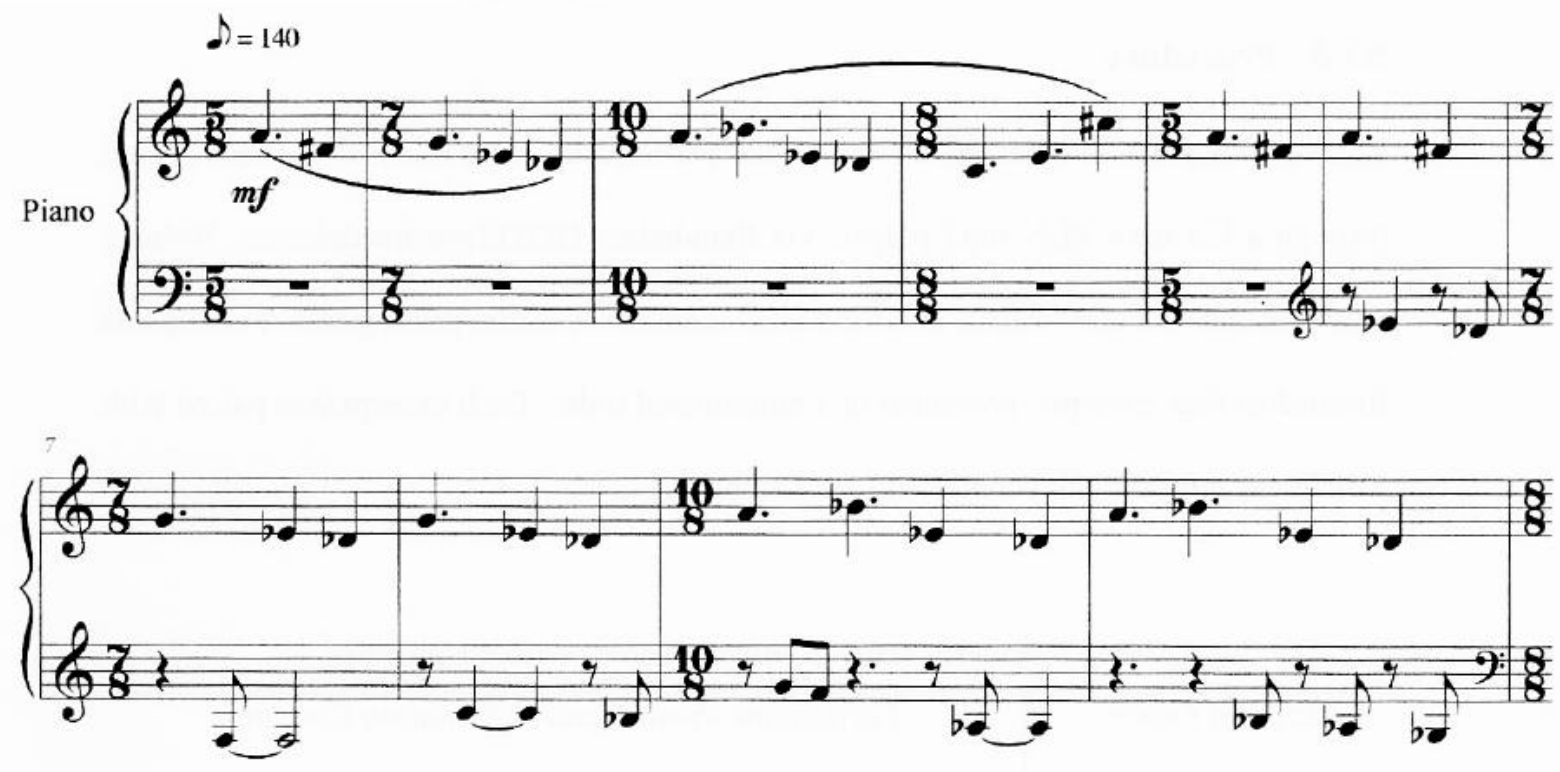

And in Saron Study No. 1 (2020) for toy piano and saron CD soundbed, a similar saturation takes place between the two 23 measure halves of the work, the first half single line (Image 13a measures 12-17), the second half, fuller textured (Image $13 \mathrm{~b}$ measures 35-40). For me, this is reminiscent of the strategy of pentimento - hinting at a fuller pattern which is gradually revealed and, in some works, lost again. 
IMAGE 13a - Saron Study No. 1 (2020) for toy piano and saron CD soundbed, mss 12-17

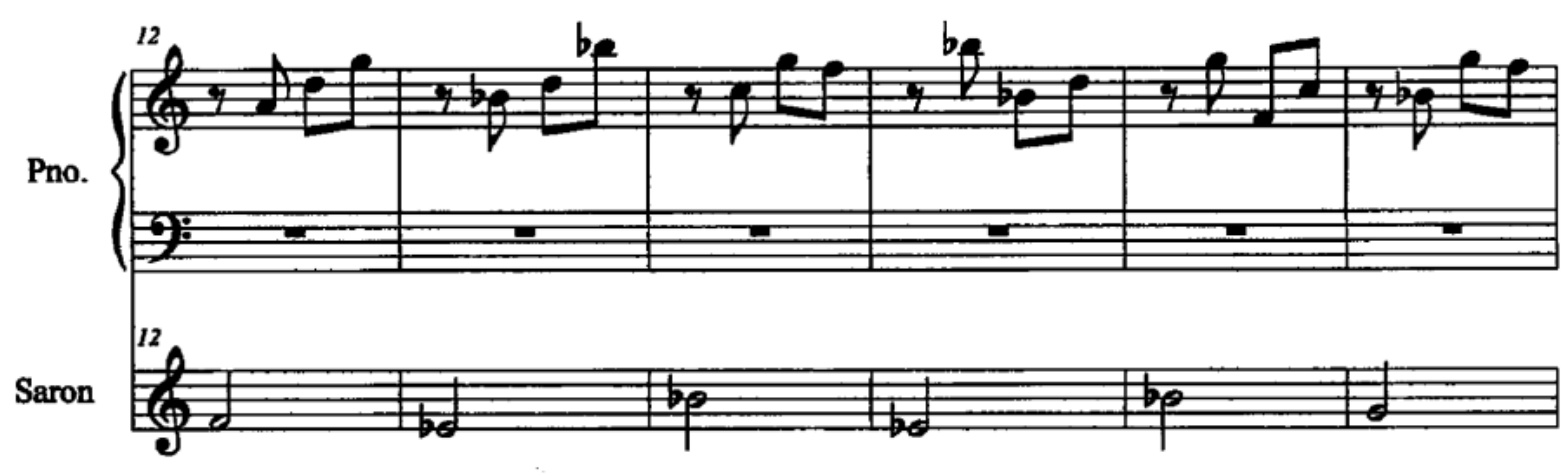

IMAGE 13b - Saron Study No. 1 (2020) for toy piano and saron CD soundbed, mss 35-40

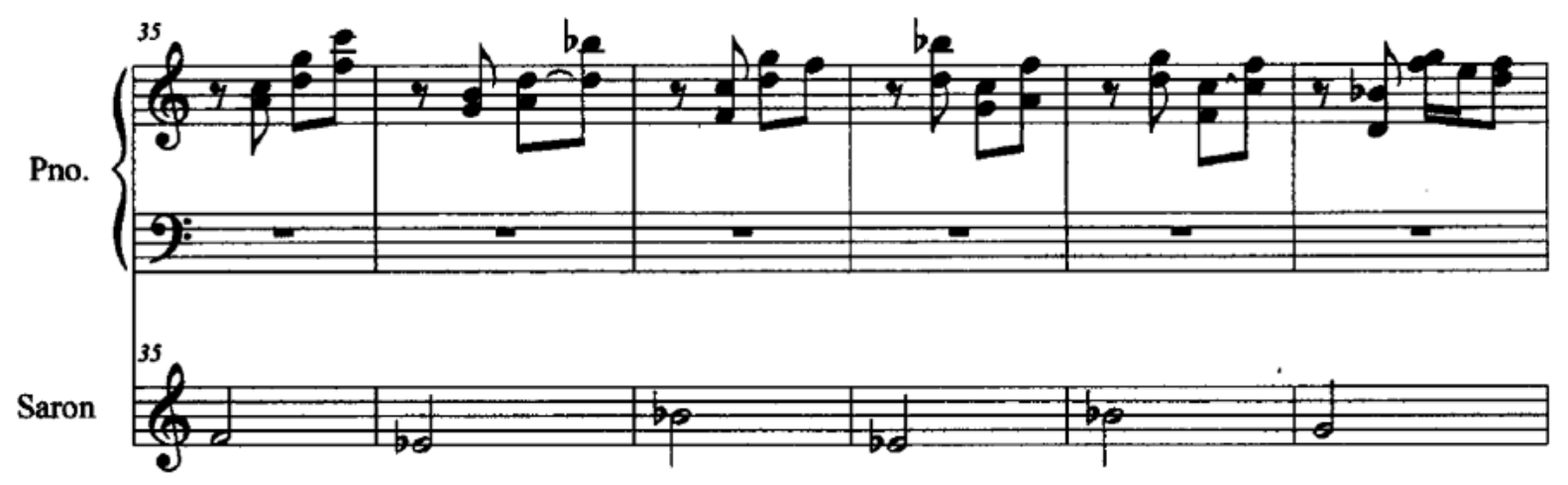

In Saron Study No. 1 the terms saturation and pentimento take on other layers of meaning because the timbre and tuning of the saron and the timbre of the toy piano together create a shimmer of conflicting sound waves, and the piece brings together the Javanese gamelan's sound world through the saron, plus the steady pulse of the gamelan, with Western toy piano, one culture merging with another.

Elizabeth Cooper's ${ }^{4}$ watercolour of the Australian rainforest tree Stenocarpus sinuatus (Firewheel Tree) depicts its wheel-like inflorescences and developing fruits. To record the details of the plant subject, Cooper (2020) does a series of sketches in graphite and creates a composition she is happy with. After carefully tracing and transferring the image to her final watercolour paper, she begins the process of applying colour. She sets down an initial, quite pale wash of watercolour which she leaves to dry before applying the next, slightly darker shade. Working from light to dark, she builds up multiple layers of watercolour, leaving highlights as she goes and creating an appropriate intensity

\footnotetext{
${ }^{4}$ Cooper's botanical illustrations are held in collections at the Royal Botanic Gardens Kew and Royal Botanic Gardens, Melbourne.
} 
and transparency of colour. To create the fine botanical detail of the subject, and to build up form and texture, she applies her dry brush technique, using a small brush with pigment but very little water. She describes this technique as "rather like drawing with paint". Petherbridge (2010) talks of how "painting participates in a spatial dance whether we want it or not: cold colours recede, warm colours appear to come forward; juxtapositions of colour set up optical vibrancies; forms expand or contract by virtue of their colour relationships” (p. 88). This description shares some observations with Cooper's description of her botanical watercolour process yet her process does include line too in the initial stages.

Drawing Firewheels for piano and toy piano (one player) (2017), was composed in 2016 for toy pianist and pianist Antonietta Loffredo and strongly influenced by the firewheel botanical drawings of Cooper. The cycle of the flowers and fruit through all stages shaped the work (Image 14), the sound gestures and sustain pedal acted as 'sound brush' colouring specified notes and note groups, the role of line is present and the possible movement of firewheel's fireworks-like flowers was also in my mind as I composed.

IMAGE 14 - Cover of the score of Drawing Firewheels for piano and toy piano (one player) (2017). Botanical drawing of Stenocarpus sinuatus (Firewheel Tree) by Elizabeth Cooper, used with permission. Score published by Wirripang Pty. Ltd.

\section{Drawing Firewheels \\ for piano and toy piano (one player)}

\section{DIANA BLOM}
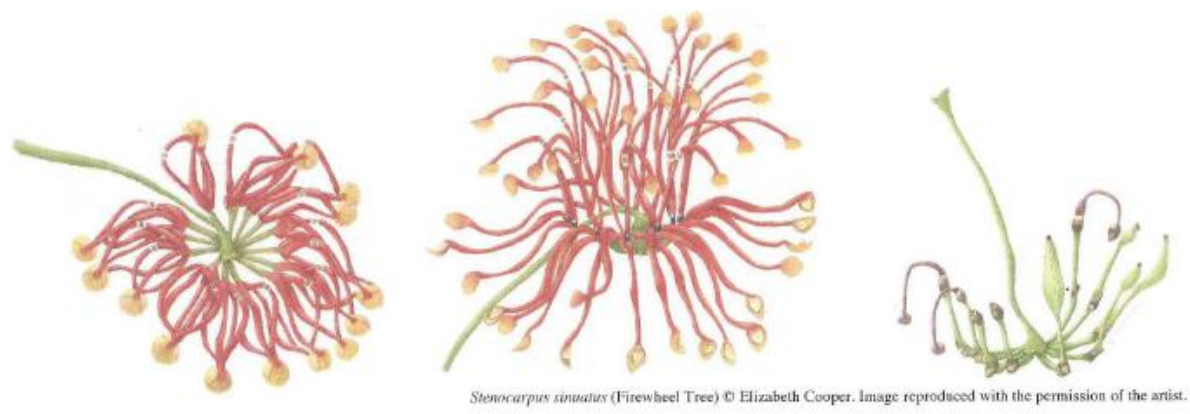

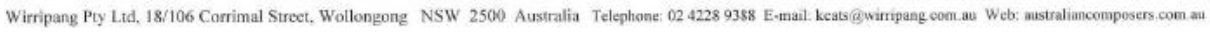


The relationship between the toy piano and piano in the work changes with each section. The opening and closing (see measures 117-119, Image 15) of Drawing Firewheels use the toy piano as a faint tracing line, bringing the spaced-out pivot notes of the piano into sharper focus.

IMAGE 15 - Drawing Firewheels for piano and toy piano (one player) (2017), mss 112-119.

(permission Wirripang Pty. Ltd.)
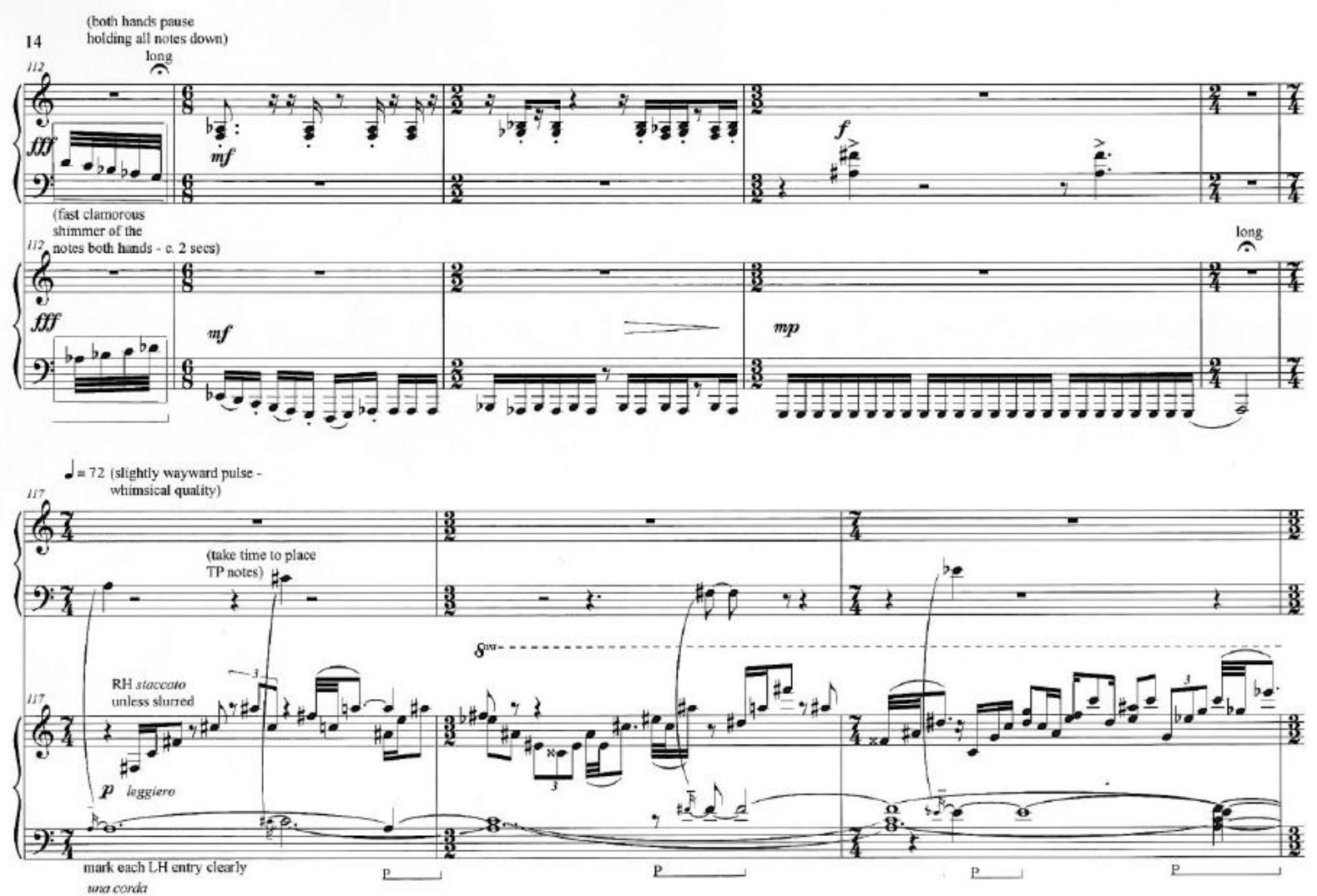

In the middle section (Image 16) the toy piano uses the pedalled sustained sound of thick piano chords as a layer on which to place Cooper's dry brush technique, through the toy piano line, bringing the slow section into sharper timbral focus. 
IMAGE 16 - Drawing Firewheels for piano and toy piano (one player) (2017), mss 56-62.

(permission Wirripang Pty. Ltd.)

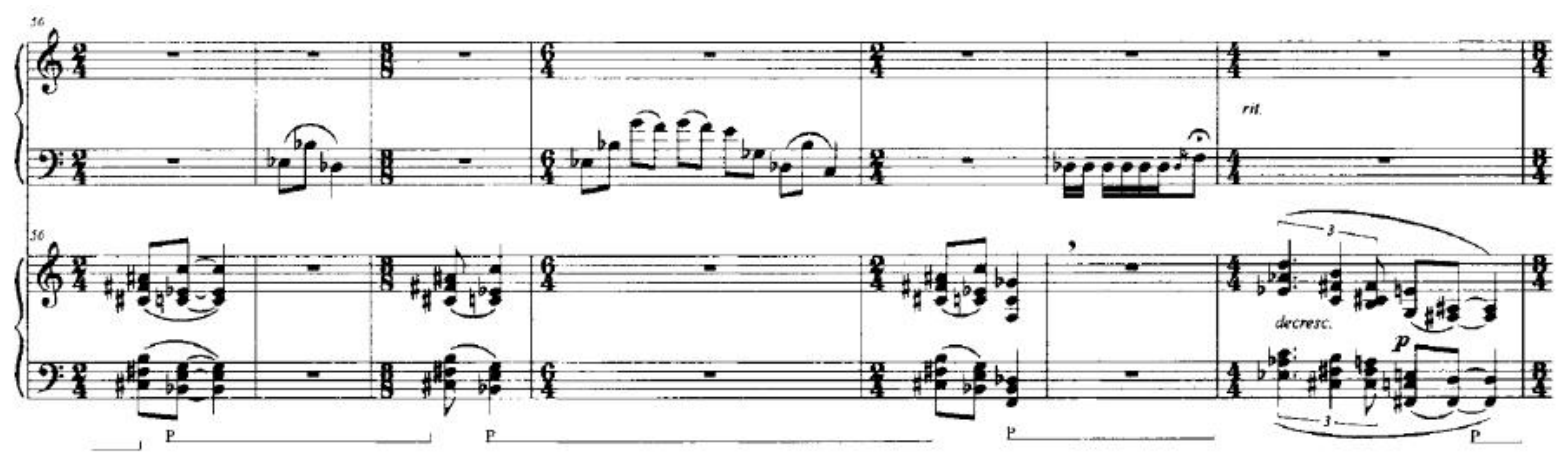

In the fast, middle section, the instruments are working together to build active, loud textures before a short lyrical melody and accompaniment section (toy piano melody, piano accompaniment). There is a return to the fast, active texture but this time with a splintering between the two instruments as they swap roles, at times the toy piano in accompanying role, piano with interjections (Image 17 measures 103-106), and vice versa (Image 15, measures 113-115), Cooper's dry brush technique again.

IMAGE 17 - Drawing Firewheels for toy piano and piano (one player) (2017), mss 103-106. (permission Wirripang Pty. Ltd.)

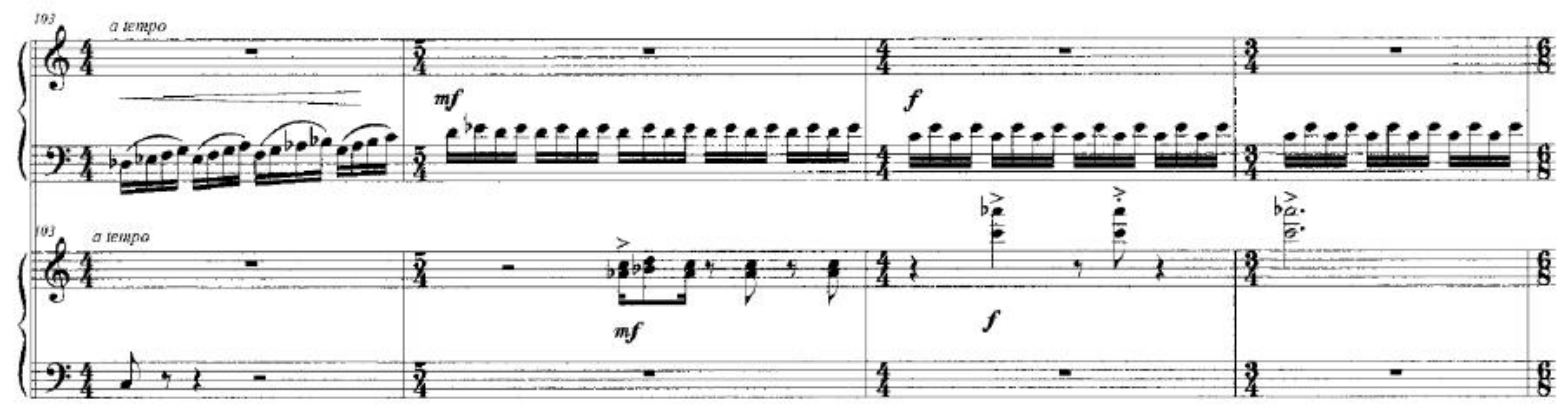

A series of runs between the two instruments leads to a truncated return of the opening texture with the toy piano again tracing and highlighting the line of the piano figure's pivot notes. It might be drawing a long bow but the idea of the stages of the Firewheel's development from fruit to flower and return to fruit again, which underpins the structure of the work, is a fauxpentimento technique, not necessarily heard but very present. 
I'm not a drawer or painter but have written an improvisation frame for toy piano and manualwind music box, Biffo in the toy box, in 2012 (Image 18). And I'm now aware that graphic scores such as this require similar thinking when performed - that is, my primitive images require careful consideration of texture line in the score and then in interpretation by the performers.

IMAGE 18 - Biffo in the toy box (2014) for toy piano and manual-wind music box, Strange Terrain - a new anthology of New Zealand graphic scores 1965-2012 (permission Wai-te-ata Music Press)

\section{Biffo in the thos Box}

\section{Improvisation frame for toy piano and manual-wind music box Diana Blom

Subtitle* -

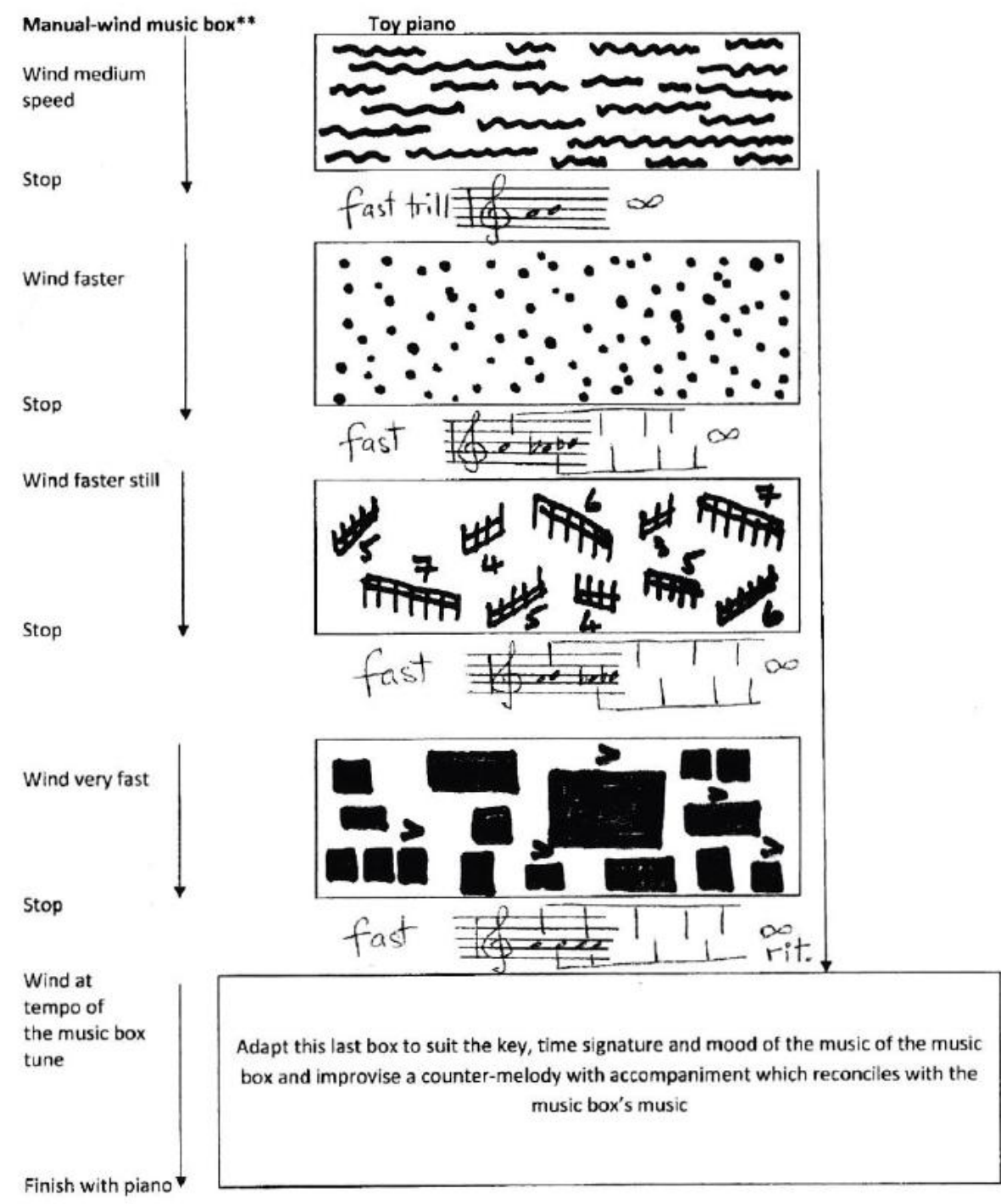

- the subtitle and last box depend on the music of the music box. Choose a subtitle relevant to the music box's piece. The first performance on 1 "Nov., 2012, had the sub-tite, 'Romeo and juliet Work it Out', as the music box's music was 'Romeo and suliet'.

*. The music box must have a handle and be able to be manually controlled by the player. Players to face each other. 
My musical response to hand drawing techniques is largely an 'expressive response', to use Duncan's (2017) term, yet there is an element of, not non-musical mathematical parallels, but trying to use the drawing techniques in a way similar to how artists use them, but in sound. Whether the architectural proportions represented in the Dufay, Duncan and Maxwell Davies works are accurately represented in the music doesn't matter musically (it would architecturally), and whether my musical outcomes bear any overt relationship to drawing, doesn't matter either. But these drawing techniques foster ideas for me. Petherbridge discusses other techniques such as chiaroscuro, grisaille, parerga, reverso, ébauche among others and looking on the web there are many other drawing and painting strategies or techniques waiting to be discovered. All potentially offer ideas which I can draw into sound but the few I have worked with and discussed above have taken my compositional thinking into different directions and encouraged rethinking and new thinking in sound for the toy piano and other sound sources.

\section{REFERENCES}

BLOM, Diana. Biffo in the Toy Box (2012) for toy piano and manual wind music box. Strange Terrain - a new anthology of New Zealand graphic scores 1965-2012, editor Jack Body. Wellington, New Zealand: Wai-te-ata Music Press, 2014. Music score.

Music score.

. Cat's Play for toy piano, castanets, horn and bell. Wollongong: Wirripang Pty. Ltd., 2019.

. Drawing Firewheels for piano and toy piano (one player). Wollongong: Wirripang Pty.

Ltd., 2017. Music score.

....earth tones... for toy piano. Wollongong: Wirripang Pty. Ltd., 2014. Music score.

. Saron Study No. 1 for toy piano and saron CD soundbed, unpublished, 2020.

. The Blue Ice Cave for piano and toy piano (one player). Wollongong: Wirripang Pty. Ltd., 2016. Music score.

. Through Shadows for toy piano. Wollongong: Wirripang Pty. Ltd., 2020. Music score.

BONSHEK, Corrina. Eve Duncan's Butterfly Modernism. Australian Music Centre resources. Resonate, 2015, 11 June. Available at: https://www.australianmusiccentre.com.au/article/eveduncan-s-butterfly-modernism. Accessed 3 June 2019.

COOPER, Elizabeth. Sydney, Australia. 7 May, 2020. Email conversation.

DAVIES, Peter Maxwell. Notes in the booklet to Maxwell Davies: Symphony No. 3, 2-3. BBC Philharmonic, Sir Peter Maxwell Davies, conductor. CD recording. Collins Classics 14162. St Mary 
Cray, Orpington, Kent: Lambourne Productions Limited, 1994. Available at Wikipedia https://en.wikipedia.org/wiki/Symphony_No. 3 _(Davies)\#CITEREFDavies1994. Accessed on 21 May 2020.

DUNCAN, Eve. Butterfly Modernism: composing with non-musical mathematics of architecture, East Asian aesthetics, and Steiner spirituality, 2017. Doctor of Creative Arts, Western Sydney University, Australia.

KIRZINGER, Robert. Steve Reich Drumming - San Francisco Contemporary Music Players press release. 2015. Available at https://sfcmp.org/drumming/. Accessed_3 June 2019.

PETHERBRIDGE, Deanna. The Primacy of Drawing - bistories and theories of practice. Yale University Press: New Haven and London, 2010.

REICH, Steve. Steve Reich - Writings about Music. Halifax, Canada: The Press of the Nova Scotia College of Art and Design, 1974.

SAMUEL, Claude. Olivier Messiaen: Musique et couleur, Paris: P. Belfond, English translation by E. T. Glasow, 1994, Portland, USA: Amadeus Press, p. 77, 1986.

SOMFAI, Laszio. Haydn's Esterhaza. The Influence of Architecture on Music. The New Hungarian Quarterly, 23.87, Fall, 1982.

WARREN, Charles. Brunelleschi's Dome and Dufay's Motet, The Musical Quarterly, 59, 1, 92105, 1973.

\section{ABOUT THE AUTHOR}

Diana Blom, composer and keyboard player (piano, harpsichord, toy piano), has published on higher education music performance, the artist as academic, preparing new music for performance. She has co-curated several composition/performance/CD projects including: Shadows and Silhouettes - new music for solo piano with a WesternChinese confluence; Antarctica - new music for piano and/or toy piano; and Multiple Keyboards - new music for pianos, toy pianos. Scores and CDs are published by Wirripang Pty. Ltd., Orpheus Music and Wai-te-Ata Press. Music Composition Toolbox, a co-authored composition textbook, is published by Science Press. Diana is Associate Professor of Music at Western Sydney University. ORCID: https://orcid.org/0000-0001-6527-6233. Website: www.dianablom.com. E-mail: d.blom@westernsydney.edu.au 